\title{
Atmosphere Revitalization Technology Development for Crewed Space Exploration
}

\author{
Jay L. Perry, Robyn L. Carrasquillo, and Danny W. Harris \\ NASA Marshall Space Flight Center, Marshall Space Flight Center, Alabama, 35812
}

\begin{abstract}
As space exploration objectives extend human presence beyond low Earth orbit, the solutions to technological challenges presented by supporting human life in the hostile space environment must build upon experience gained during past and present crewed space exploration programs. These programs and the cabin atmosphere revitalization process technologies and systems developed for them represent the National Aeronautics and Space Administration's (NASA) past and present operational knowledge base for maintaining a safe, comfortable environment for the crew. The contributions of these programs to the NASA's technological and operational working knowledge base as well as key strengths and weaknesses to be overcome are discussed. Areas for technological development to address challenges inherent with the Vision for Space Exploration (VSE) are presented and a plan for their development employing unit operations principles is summarized.
\end{abstract}

\section{Introduction}

$\mathrm{O}$ VER the course of the United States' space exploration program, the National Aeronautics and Space Administration (NASA) has developed and operated a variety of environmental control and life support (ECLS) systems to achieve a range of space exploration objectives. Beginning with Project Mercury and continuing through the International Space Station (ISS) program, the technological solutions to safely support human life in the hostile space environment have evolved from those required to support a single astronaut for minutes or hours to those supporting for crews of three or more for months and ultimately years.

The Vision for Space Exploration (VSE) presents new challenges and performance standards that build on and extend the NASA's experience and working knowledge of ECLS systems. Objectives specified by the VSE are the following: ${ }^{1}$

1) Implementing sustained, affordable space exploration programs

2) Extending human presence across the solar system

3) Developing innovative technologies, knowledge, and infrastructure in support of exploration decisions

4) Promoting international and commercial participation to further the United States' scientific, security, and economic interests

The principle aim of the NASA's efforts to develop the next generation of ECLS systems is to realize objectives through enabling technological development and applied performance characterization. Developing atmosphere revitalization process technologies and characterizing their performance for application to NASA's next generation crewed spacecraft is a leading initiative toward realizing the VSE's goals.

\section{Atmosphere Revitalization On Board Crewed Spacecraft-Past and Present}

The atmosphere revitalization systems developed to enable past and present space exploration goals form the NASA's working knowledge base for process technologies and equipment embodiments capable of maintaining a safe, comfortable cabin environment for space explorers. Table 1 summarizes the basic features of atmosphere supply and revitalization technologies employed on board various crewed spacecraft. ${ }^{2-7}$ Of these, the experiences gained from the Apollo, Skylab, and ISS programs are most relevant to meeting the goals set forth by the VSE. Both Shyläb and ISS have demoñstrated the utility and limitations of combined regenerable and non-regenerable opensystem processes for maintaining cabin atmospheric quality while the challenge associated with surface dust and debris that can be brought into a surface habitat or surface exploration vehicle became apparent during the Apollo program. 
Table. 1. Atmosphere revitalization aboard crewed spacecraft-past and present.

\begin{tabular}{|c|c|c|c|c|}
\hline PROJECT & $\begin{array}{c}\text { MISSION } \\
\text { DURATION }\end{array}$ & $\begin{array}{l}\text { CABIN } \\
\text { VOLUME } \\
\left(\mathrm{m}^{3}\right)\end{array}$ & $\begin{array}{l}\text { CREW } \\
\text { SIZE }\end{array}$ & TECHNOLOGICAL APPROACH \\
\hline Mercury & 34 hours & 1.56 & 1 & $\begin{array}{l}\text { Atmosphere: } 100 \% \mathrm{O}_{2} \text { at } 34.5 \mathrm{kPa} \text {. } \\
\text { Atmosphere supply: } \mathrm{G} \text { as at } 51.7 \mathrm{MPa} \text {. } \\
\mathrm{CO}_{2} \text { removal: LiOH. } \\
\text { Trace contaminants: Activated carbon. }\end{array}$ \\
\hline Gemini & 14 days & 2.26 & 2 & $\begin{array}{l}\text { Atmosphere: } 100 \% \mathrm{O}_{2} \text { at } 34.5 \mathrm{kPa} \text {. } \\
\text { Atmosphere supply: Supercritical storage at } \\
\quad 5.86 \mathrm{MPa} \text {. } \\
\mathrm{CO}_{2} \text { removal: LiOH. } \\
\text { Trace contaminants: Activated carbon. }\end{array}$ \\
\hline Apollo & 14 days & 5.9 & 3 & $\begin{array}{l}\text { Atmosphere: } 100 \% \mathrm{O}_{2} \text { at } 34.5 \mathrm{kPa} \text {. } \\
\text { Atmosphere supply: Supercritical storage at } \\
\quad 6.2 \mathrm{MPa} \text {. } \\
\mathrm{CO}_{2} \text { removal: LiOH. } \\
\text { Trace contaminants: Activated carbon. }\end{array}$ \\
\hline Skylab & 84 days & 361 & 3 & $\begin{array}{l}\text { Atmosphere: } 72 \% \mathrm{O}_{2} / 28 \% \mathrm{~N}_{2} \text { at } 34.5 \mathrm{kPa} \text {. } \\
\text { Atmosphere supply: } \mathrm{Gas} \text { at } 20.7 \mathrm{MPa} \text {. } \\
\mathrm{CO}_{2} \text { removal: Type } 13 \mathrm{X} \text { and } 5 \mathrm{~A} \text { molecular } \\
\text { sieves regenerated by vacuum swing. } \\
\text { Trace contaminants: Activated carbon. }\end{array}$ \\
\hline Space Shuttle & 14 days & 74 & 7 & $\begin{array}{l}\text { Atmosphere: } 21.7 \% \mathrm{O}_{2} / 78.3 \% \mathrm{~N}_{2} \text { at } 101 \mathrm{kPa} \\
\text { Atmosphere supply: } \mathrm{Gas} \text { at } 22.8 \mathrm{MPa} \\
\mathrm{CO}_{2} \text { removal: } \mathrm{LiOH} \\
\text { Trace contaminants: Activated carbon and } \\
\text { ambient temperature } \mathrm{CO} \text { oxidation }\end{array}$ \\
\hline $\begin{array}{l}\text { International } \\
\text { Space Station }\end{array}$ & 180 days & Up to 600 & 3 to 6 & $\begin{array}{l}\text { Atmosphere: } 21.7 \% \mathrm{O}_{2} / 78.3 \% \mathrm{~N}_{2} \text { at } 101 \mathrm{kPa} \\
\text { Atmosphere supply: Gas at } 20.7 \mathrm{MPa} / \text { water } \\
\text { electrolysis } \\
\mathrm{CO}_{2} \text { removal: Silica gel with type } 13 \mathrm{X} \text { and } 5 \mathrm{~A} \\
\text { molecular sieves regenerated by } \\
\text { vacuum/temperature swing } \\
\mathrm{CO}_{2} \text { reduction: Sabatier reactor (scar for } \\
\text { future addition) } \\
\text { Trace contaminants: Activated carbon and } \\
\text { thermal catalytic oxidation }\end{array}$ \\
\hline
\end{tabular}

\section{A. Atmosphere Revitalization Process Classification}

Atmosphere revitalization processes can be classified into two basic categories-separations and reactions. Separations include physical adsorption, absorption, and mechanical filtration processes. Reactions include chemical adsorption, oxidation, and reduction processes. Phase-change processes are typically employed for humidity control. NASA's present capabilities include equipment on board the Shuttle orbiter and ISS employing separations- and reaction-based processes to remove carbon dioxide $\left(\mathrm{CO}_{2}\right)$ from the cabin atmosphere. Trace volatile organic compounds (VOCs) are removed primarily via separations processes. Some trace atmospheric components such as formaldehyde, carbon monoxide, and methane require reactive processes for achieving effective control. Particulate matter (PM) is typically removed from the cabin atmosphere by separations processes employing mechanical filtration. Inertial techniques may also be used for PM control.

\section{B. Atmosphere Revitalization Processes-Shuttle and ISS Embodiments}

Operational atmosphere revitalization equipment on board the Shüttle orbiter and ISS employ both separationand reaction-based processes. The summary provided by Table 1 shows the atmosphere revitalization processes used on board the Shuttle orbiter are fundamentally the same as those used for the Mercury, Gemini, and Apollo programs. The primary difference lies in the specific hardware embodiments whereby bed geometry and process flow rates may vary. Also, the cabin total pressure condition is different. Shuttle processes rely predominantly on 
expendable resources while the ISS ECLS system is composed of processes that employ in-situ regeneration. The following is a brief summary of the atmospheric purification processes used on board the Shuttle orbiter and ISS.

1. Atmosphere Revitalization Processes On Board the Shuttle Orbiter and Spacelab Module

Carbon dioxide partial pressure control is provided on board the Shuttle orbiter by contacting the cabin atmosphere with granular lithium hydroxide $(\mathrm{LiOH})$. The $\mathrm{LiOH}$ reacts irreversibly with $\mathrm{CO}_{2}$ to form lithium carbonate $\left(\mathrm{Li}_{2} \mathrm{CO}_{3}\right)$ and water $\left(\mathrm{H}_{2} \mathrm{O}\right)$. Carbon dioxide removal by reversible reaction with functionalized amines has been demonstrated on board the Shuttle orbiter but is not presently deployed on board an operational spacecraft or space habitat. In this process, reversible reaction between carbon dioxide and the functionalized amine is promoted by a vacuum-swing process. ${ }^{8}$

Each LiOH canister contains a small amount of granular activated carbon (GAC) that serves to protect the $\mathrm{LiOH}$ from contaminants that may interfere with $\mathrm{CO}_{2}$ 's reaction with $\mathrm{LiOH}$. The GAC also provides some degree of odor control but is not sized sufficiently to serve as a broad spectrum trace contaminant removal mechanism. Targeted trace contaminant control is provided using platinized GAC (Pt-GAC) contained in a low volumetric flow canister known as the ambient temperature catalytic oxidation (ATCO) unit. The Pt-GAC, is designed to promote carbon monoxide (CO) oxidation to $\mathrm{CO}_{2}$ at normal cabin temperature conditions. A small amount of GAC is included in the ATCO unit to protect the Pt-GAC material from poisoning., 90

Overall, the bulk of the trace contaminant removal on board the Shuttle orbiter occurs via absorption by humidity condensate. Absorption by humidity condensate occurs naturally and has been shown to be a significant removal mechanism for water-soluble chemical contaminants. ${ }^{11,12}$ The cabin temperature and humidity control equipment on board the Shuttle orbiter, however, are not specifically designed to provide or optimized to enhance this function. The active contamination control equipment design also does not take credit for the assist provided by contaminant absorption by humidity condensate. Such an approach provides a built-in design safety factor. This phenomenon must be accounted for if there is a desire to reclaim the humidity condensate for human consumption. ${ }^{13}$

The Spacelab program employed the same $\mathrm{CO}_{2}$, particulate matter, and humidity control techniques used by the Shuttle orbiter. One difference was the use of a larger module specifically designed for broad spectrum trace contaminant control. The Spacelab transfer tunnel scrubber contained a layered fixed bed of GAC. The first layer consisted of GAC treated with phosphoric acid $\left(\mathrm{H}_{3} \mathrm{PO}_{4}\right)$ that targeted ammonia $\left(\mathrm{NH}_{3}\right)$ and other trace VOCs. The second layer consisted of untreated GAC. Both the first and second layers served to protect the third layer, consisting of Pt-GAC, from poisoning. ${ }^{14,15}$

\section{Atmosphere Revitalization Processes On Board the International Space Station}

The principle atmosphere revitalization processes on board the ISS are embodied by the $\mathrm{CO}_{2}$ removal assembly (CDRA) and the trace contaminant control system (TCCS). This equipment is mounted in a dedicated atmosphere revitalization subsystem (ARS) rack shown in Figure 1.

The $\mathrm{CO}_{2}$ removal assembly (CDRA) process design used on board the ISS is derived from that used on board Skylab. Both processes use zeolites to remove moisture and $\mathrm{CO}_{2}$ from the process gas stream yet achieve slightly different performance objectives. While Skylab employed a 2-bed technique with no water saving capability, the process used on board the ISS employs a 4-bed technique

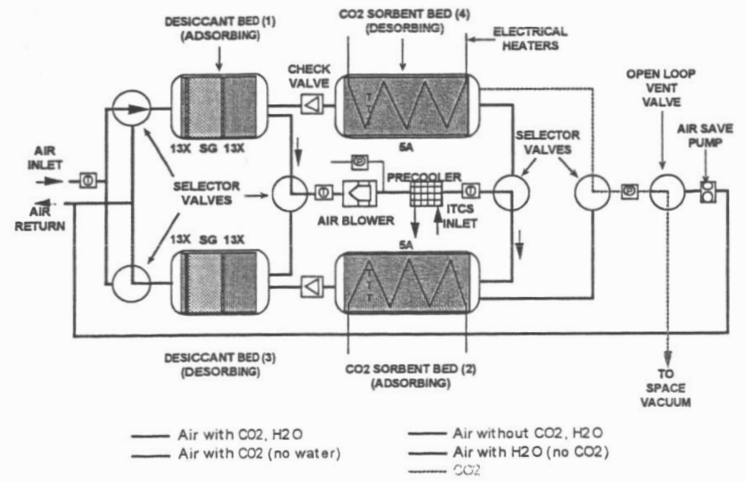

Figure 1. ISS CDRA in the ARS rack.

that allows water to be recovered for reuse. The water recovery feature is an important extension of the Skylab process design and is achieved by separating the zeolite $13 \mathrm{X}$ and $5 \mathrm{~A}$ layers contained in each bed into two distinct beds - a desiccant bed and a $\mathrm{CO}_{2}$ adsorption bed. The CDRA, shown schematically and pictorially by Figure 1 , consists of 4 adsorbent beds, a blower, an air save pump, and six selector valves. Preconditioned cabin air at its dew point enters the CDRA and flows through the adsorbing desiccant bed to remove additional water. Preconditioning the inlet air reduces the total moisture load and serves to minimize the desiccant bed size. Each desiccant bed consists of 2 layers of zeolite $13 \mathrm{X}$ separated by a layer of silica gel (SG). The process air exiting the desiccant bed typically has a dew point ranging from -62 to $-73^{\circ} \mathrm{C}$. Upon exiting the desiccant bed, the air enters one of the $\mathrm{CO}_{2}$ 
adsorption beds. Each $\mathrm{CO}_{2}$ adsorption bed contains zeolite 5A. The air exits through the regenerating desiccant bed. Exhaust air is directed back to the humidity control system to recover the moisture as condensate. ${ }^{16,17}$

Bed regeneration was accomplished on board Skylab using vacuum swing at 15-minute intervals. The capability to heat the beds to achieve more thorough regeneration was also provided. Carbon dioxide adsorption bed regeneration for the ISS CDRA is accomplished by combined vacuum/thermal swing at 144-minute intervals. During regeneration, the carbon dioxide adsorbent bed is evacuated by a pump, heated to $204{ }^{\circ} \mathrm{C}$, and exposed to space vacuum. The initial evacuation is designed to minimize overboard atmospheric gas losses. Heating the bed requires nearly $1 \mathrm{~kW}$ of power. The $\mathrm{CO}_{2}$ adsorption beds serve as thermal capacitors and heat removed from the beds after regeneration is completed is used to regenerate the desiccant beds. The energy required to recover water from the desiccant beds is quite significant causing the CDRA to be a power-intensive process. Means to further reduce the moisture load entering the CDRA process could serve to reduce its power requirement.

Contamination control on board the ISS is provided by the trace contaminant control system (TCCS). Three main components comprise the TCCS. They are an expendable activated carbon bed, a thermal catalytic oxidizer, and an expendable post-sorbent bed. Additionally, the TCCS contains a blower, flow meter, and electrical interface assembly. The TCCS has a long development history dating to the late 1960 s. Its primary design was first built and tested in the mid-1970s and has changed little since. In the ISS TCCS process design shown schematically by Figure 2, process air enters the process directly from the cabin. Unlike the CDRA, the inlet air is not processed to remove moisture. The process gas first contacts $\mathrm{GAC}$ treated with $10 \% \mathrm{H}_{3} \mathrm{PO}_{4}$ by weight. The $\mathrm{H}_{3} \mathrm{PO}_{4}$ treatment prevents $\mathrm{NH}_{3}$ from entering the thermal catalytic oxidizer where it can be converted to harmful oxides of nitrogen $\left(\mathrm{NO}_{\mathrm{x}}\right)$. Upon exiting the carbon bed, the process

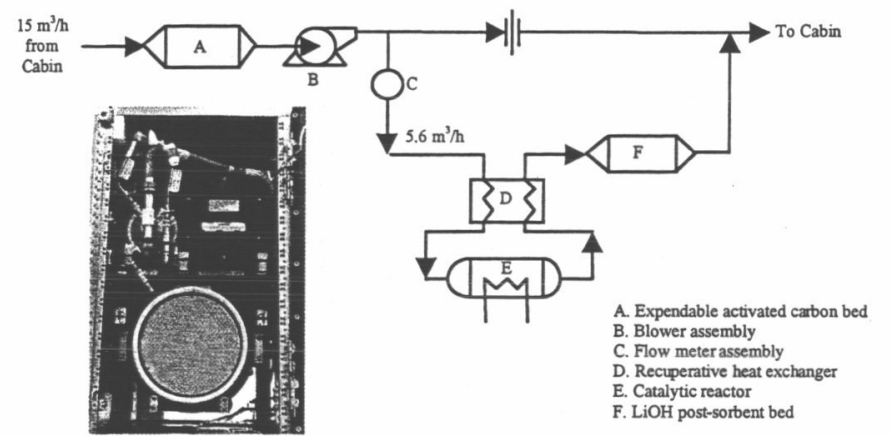

Figure 2. ISS trace contaminant control subassembly. stream splits. Approximately one-third of the air flows through the thermal catalytic oxidizer and post-sorbent bed before rejoining the bypass stream just before the system exhaust. Primary components of the thermal catalytic oxidizer are a recuperative heat exchanger, an electric heater, and a catalyst bed. The catalyst bed contains approximately $1 \mathrm{~kg}$ of $0.5 \%$ palladium (Pd) catalyst supported on alumina pellets. ${ }^{18}$

3. Atmospheric Gas Storage, Distribution, and Resource Recovery

The techniques used to store and supply atmospheric gases on board the Shuttle orbiter and ISS rely on either cryogenic or high pressure storage with appropriate conditioning. The ISS's U.S. On-orbit Segment (USOS) will ultimately include the capability to supply atmospheric oxygen via water electrolysis. The U.S. oxygen generator assembly (OGA) is shown by Figure 3..$^{19,20}$ The Russian On-orbit Segment (ROS) already possesses this capability. While tested extensively on the ground, no operational spacecraft or space habitat possesses the capability to reduce carbon dioxide to achieve minimal overboard water losses. The ISS's USOS will include a functional scar to enable deploying carbon dioxide reduction equipment on board but no flight hardware developmental work is ongoing to build that equipment.
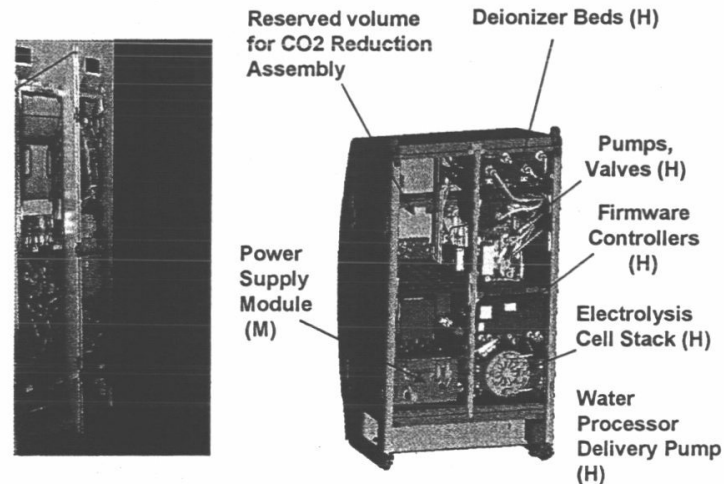

Figure 3. ISS oxygen generator assembly rack.

\section{Particulate Matter Removal Processes}

Particulate matter control on board the Shuttle orbiter is provided by course filtration with a 280 -micron $(\mu \mathrm{m})$ nominal, 300-um absolute rating. This PM control technique is designed to protect equipment from clogging and fouling rather than to remove respirable particles that may be a health hazard to humans. Similarly, particulate matter is removed from the ISS cabin atmosphere by mechanical filtration. All process air entering the cabin ventilation system is filtered. Filter elements are rated $99.97 \%$ efficient for $0.3-\mu \mathrm{m}$ PM. This performance is HEPA by definition. Filter elements typically are replaced every 2 years. ${ }^{21}$ 


\section{Enabling Capabilities for Exploration}

As crewed space exploration mission durations increase and exploration objectives extend beyond low Earth orbit, improvements are needed to further minimize atmosphere revitalization process equipment mass, power, volume, and logistics requirements. Experience has demonstrated that atmosphere revitalization process technologies based on adsorption and catalytic oxidation work well; however, process inefficiencies and the continued reliance on expendable resources present challenges to extending the boundaries of space exploration. Identifying opportunities to attack these inefficiencies leading to a highly efficient, autonomous atmosphere revitalization process equipment design are critical for meeting the challenges presented by the VSE. ${ }^{22}$

To realize the goals established for the VSE, improved open- and closed-system process designs for atmosphere revitalization must be developed. Open-systems employing unit operations for humidity, carbon dioxide, and trace VOC control are needed for near-term applications in low Earth orbit (LEO) and transportation between LEO and the Moon. These systems may be a combination of regenerative and non-regenerative processes as influenced by mission specifications. Processes utilizing physical adsorption or reversible chemical processes capable of regeneration using vacuum and/or temperature swing are leading process technologies. Atmospheric gas storage to support transportation in LEO or to the Moon will be based on presently understood technologies such as high pressure and cryogenic storage. The ability to economically fill storage tanks in flight will be needed. Controlling PM for transportation applications will also use existing mechanical filtration techniques.

Short-duration lunar surface exploration can initially use exploration vehicle-derived systems. Controlling particulate matter becomes more difficult as soil and dust from extravehicular activity (EVA) becomes an issue. A variety of inertial separation, electrostatic, HEPA, and ultra-low particulate air (ULPA) filtration techniques will need to be developed to protect the crew, the surface habitat, and equipment from the dust and debris. Developing the means for high-pressure oxygen generation combined with the ability to refill storage tanks for exploration vehicle systems becomes important.

Long duration missions, including Mars transit and vicinity operations, require a closed ECLS system design illustrated by Figure 4. Functional areas are shown and in this concept there is opportunity for improvement. Notice that byproducts are vented from the $\mathrm{CO}_{2}$ reduction function. To achieve maximum process closure, efforts must be made to find a use for these byproducts or develop process technologies suitable for recovering the byproducts. To realize such an achievement requires an end-to-end, integrated process design approach. The resulting atmosphere

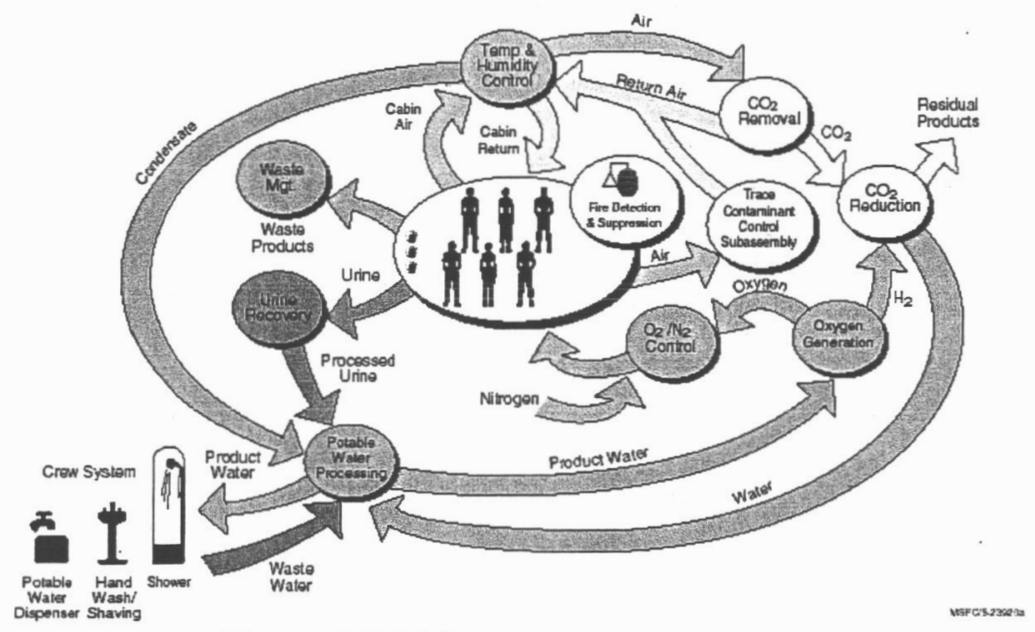

Figure 4. ECLS process functions. revitalization process must remove trace VOCs and carbon dioxide, reduce the carbon dioxide, and limit overboard water losses to those attributed only to overboard atmospheric leakage and concentrated process wastes. Process designs based on regenerable adsorption, thermal oxidation, and thermal reduction processes are the most viable candidates.

\section{Developmental Approach for Candidate Process Technologies}

A variety of process technologies will be pursued initially to address immediate process technology performance deficiencies. Given that the scope of the VSE spans short duration missions to the ISS as well as lunar surface exploration and beyond, the process technologies selected for development must address a wide range of challenges. Experience gained from past space exploration programs and opportunities to leverage existing process technológies for meeting the VSE goals will be considered as appropriate. Already, the atmosphere revitalization process equipment designs in use on board the ISS have provided a wealth of information and operational experience that can lead to improvements in ECLS system logistics support as well as process equipment robustness and complexity. ${ }^{23}$ 


\section{A. Unit Operations as a Developmental Basis}

A functional approach using the concept of unit operations serves as the basis for process technology selection and process design. ${ }^{24}$ Using the concept of unit operations breaks the overall atmosphere revitalization process design into smaller processing steps that are more easily characterized individually for ultimate integration. ${ }^{25}$ Systematically evaluating and developing each unit operation that is common to all VSE process design embodiments simplifies the challenge of developing an end-to-end atmosphere revitalization process design that addresses past and present inefficiencies associated with mass, power, volume, logistics support, and operational autonomy. Implementing robust design principles as a guiding technique for optimization at both the unit operation and atmosphere revitalization process levels is at imperative to achieve success. Traditional compartmentalized design approaches that produce parallel processing trains for each function will not achieve the desired result. A functional, unit operations approach allows interaction between processing steps to be understood via rigorous engineering analysis and targeted testing. Modular process designs that can be more rapidly adapted to changing exploration objectives and goals may also result. The principle atmosphere revitalization functions to be addressed as unit operations for near-term VSE objectives include the following:
1) Process gas drying
2) Carbon dioxide removal
3) Trace chemical contaminant removal
4) Particulate matter removal
5) Atmospheric gas storage
6) Atmospheric gas distribution
7) Atmospheric gas conditioning

To extend human presence beyond low Earth orbit for extended periods to establish a permanent human presence throughout the solar system as specified by the VSE, these unit operations must be supplemented by the following:

1) Atmospheric gas generation with high pressure capability

2) Resource recovery

3) In-situ resource utilization

\section{B. Candidate Process Technologies for Selected Unit Operations}

Candidate process technologies must address specific weaknesses of the atmosphere revitalization unit operations as presently understood. Integrating the unit operations into an overall, efficient atmosphere revitalization process design uses the knowledge and operational experience acquired via developmental projects. The developmental projects are selected based on criteria that include technological relevance, risk reduction potential, and return on investment. ${ }^{26}$ All efforts are made to avoid relying excessively on technology readiness level (TRL) as a driving project selection criterion as has been the practice for more recent space exploration programs such as ISS. ${ }^{27}$ Developmental project performance is measured relative to metrics that are based on VSE applications. The project performance metrics serve to guide decisions on adding, retaining, or terminating individual projects. Process technology developmental areas being pursued to address various process inefficiencies and to meet the challenges set forth by the VSE are the following:

1) Process gas drying-membrane-based process technologies. ${ }^{28}$

2) Carbon dioxide removal-improved chemisorbent media, improved physical adsorption media, novel adsorbent media substrates and bed packing geometries, vacuum swing adsorption processes, combined vacuum/temperature swing adsorption processes, reversible reactive processes. ${ }^{29-31}$

3) Trace chemical contaminant removal-regenerable adsorption media, novel adsorbent media substrates and bed packing geometries, improved thermal oxidation reaction designs, novel catalyst substrates and reactor geometries, highly efficient recuperative heat exchanger designs. ${ }^{32}{ }^{-37}$

4) Particulate matter removal - inertial separation $(10-\mu \mathrm{m})$, electrically-enhanced filtration $(<0.1-\mu \mathrm{m})$, electrostatic precipitation $(<0.1-\mu \mathrm{m})$, and HEPA filtration $(0.3-\mu \mathrm{m})$ system designs.

5) Atmospheric gas storage, distribution, and conditioning - storage tank recharging equipment; high pressure, cryogenic, and supercritical storage.

6) Atmospheric gas generation-high pressure oxygen production via water electrolysis

7) Resource recovery and use-carbon dioxide reduction processes to carbon product, in-situ resource utilization.

8) Supporting infrastructure-improved blowers, valves, and process monitoring and control instrumentation. 
All process technology integration will employ well-developed robust design practices to produce the greatest end-to-end process performance and operational efficiencies. An early integrated process technology concept is shown by Figure $5 .^{38}$ In this concept, process gases pass through a first unit operation to remove . chemical contaminants and PM that could foul regenerable beds. The regenerable beds function to remove $\mathrm{CO}_{2}$ and moisture. A catalytic oxidation stage removes light chemical contaminants such as methane $\left(\mathrm{CH}_{4}\right)$, carbon monoxide $(\mathrm{CO})$, and methanal $\left(\mathrm{CH}_{2} \mathrm{O}\right)$. This operation may be carried out at high temperature or ambient temperature depending on the exploration objective. Ambient temperature catalysis does not require a recuperative heat exchanger stage. Figure 6 illustrates a modular extension of the core concept illustrated by Figure $5 .^{39}$ In this concept, two regenerable process stages are used-one for removing trace chemical contaminants and one for removing $\mathrm{CO}_{2}{ }^{40}$

Candidate process technologies for the AR process design concepts include the following:

1) Activated carbon or other microporous adsorbents for expendable high molecular weight trace component removal unit operations.

2) $Y$ zeolites or functionalized amines for $\mathrm{CO}_{2}$ removal unit operations.

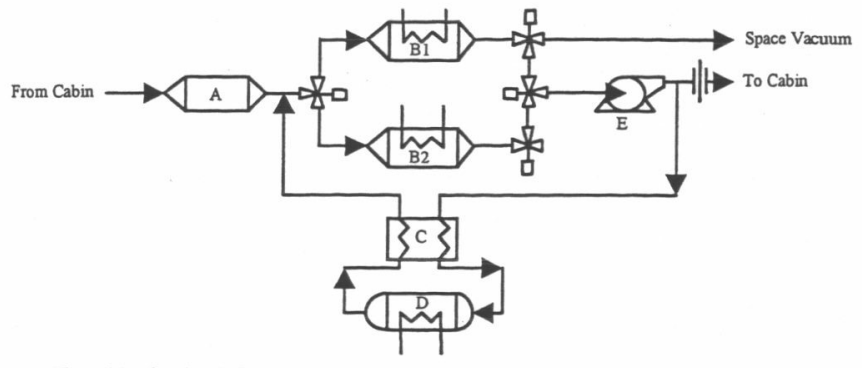

A. Expendable Guard Bed - Remove compounds having high molecular weight and low volatility. B1. Regenerable Module 1-Remove $\mathrm{CO}_{2}$ and moisture.

B2. Regenerable Module $2-\mathrm{CO}_{2}$ and moisture.
C. Recuperative Heat Exchanger - Required only if thermal catalytic oxidation employed.

D. Catalytic Reactor Assembly - Removes $\mathrm{CH}_{4}, \mathrm{H}_{2}, \mathrm{CO}$, light alcohols and aldehydes
E. Blower/Air Save Pump Assembly

Figure 5. AR process design concept.

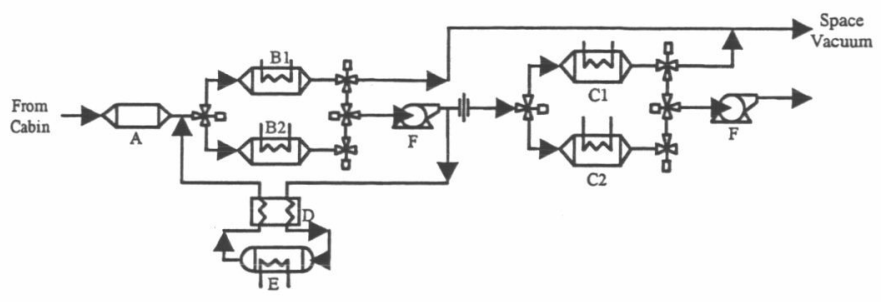

A. Expendable Guard Bed-Remove compounds having high molecular weight and low volatility

B1. Regenerable AdsorbentModule 1-Remove $\mathrm{NH}_{3}$, light VOCs, and acid gases,

B2. Regenerable AdsorbentModule 2- Remove $\mathrm{NH}_{3}$, light VOCs, and acid gases.

Cl. Regenerable $\mathrm{CO}_{2}$ Adsorbent Module 1-Remove $\mathrm{CO}_{2}$

C2. Regenerable $\mathrm{CO}_{1}$ Adsoben Modve 1-Remove CO.

D. Recuperadve Heat Exchanger

oves $\mathrm{CH}_{4}, \mathrm{H}_{2}, \mathrm{CO}$, light alcohols and aldehydes.

Figure 6. Modular AR process design.

3) Catalysts such as platinized tin oxide $\left(\mathrm{Pt} / \mathrm{SnO}_{2}\right)$ for ambient temperature $\mathrm{CO}$ oxidation unit operations.

4) Engineered ultra-short channel monolithic substrates for thermal oxidation catalysts and thermally regenerable adsorbents to enhance maintainability, reliability, and energy efficiency.

\section{Basic Design Requirements}

Basic design requirements relating to atmosphere revitalization for the Crew Exploration Vehicle (CEV) and the Lunar Surface Ascent Module (LSAM) are derived from early exploration architectural documents. Detailed requirements are under development. Available requirements of interest to atmosphere revitalization process designers are summarized by Table 2. Many of these design parameters are within the experience base of past and present space exploration programs. Beyond these parameters, any atmosphere revitalization process equipment will need to be able to function after exposure to vacuum. ${ }^{41,42}$

Table 2. CEV and LSAM early design parameters.

\begin{tabular}{|l|c|c|}
\hline \multirow{2}{*}{ PARAMETER } & \multicolumn{2}{c|}{ VALUE } \\
\cline { 2 - 3 } & CEV & LSAM \\
\hline Maximum mission duration (days) & 16 & - \\
\hline Normal mission duration (days) & 12 & 5 \\
\hline Passive duration (days) & 180 & 180 \\
\hline $\mathrm{CO}_{2}$ daily average crew exposure (Pa) & 707 & 707 \\
\hline Trace chemical contaminant concentration* & $<$ SMAC** & $<$ SMAC \\
\hline Crew size & 6 & 4 \\
\hline Pressurized volume $\left(\mathrm{m}^{3}\right)$ & 22.4 & 29.2 \\
\hline Cabin pressure (kPa) & 65.5 & 65.5 \\
\hline $\mathrm{O}_{2}$ partial pressure $(\%)$ & 30 & 30 \\
\hline Number of extravehicular activities & - & 4 \\
\hline *Recommended, not yet specified. & $* *$ SMAC $=$ spacecraft maximum allowable concentration \\
\hline
\end{tabular}




\section{Timetable for Development}

The timetable for addressing the challenges presented by the VSE is aggressive. Retiring the Shuttle orbiter by 2010 drives the inherent urgency with the timetable. Parallel efforts to achieve the VSE goals are the following:

1) Return the Shuttle orbiter to flight status and move toward retirement after ISS assembly is completed

2) Complete ISS assembly by 2010 and focus research on crew health risks and countermeasures

3) Develop the Shuttle orbiter's replacement with first risk reduction flight in 2011

4) Develop enabling infrastructure for lunar surface exploration and sustained exploration missions To meet the aggressive developmental timetable, process technologies for application to the Crew Exploration Vehicle (CEV) are the first priority. The objective is to characterize several process technologies that will constitute the core unit operations of the atmosphere revitalization system by the CEV preliminary design review scheduled for 2007. Candidate process technologies include reversible reactive and physical adsorption $\mathrm{CO}_{2}$ removal combined with moisture removal and trace chemical contaminant control process steps. Most of these process technology development efforts will benefit greatly from experience gained from the Shuttle orbiter and ISS programs as well as the lessons learned during Skylab. The core atmosphere revitalization process design resulting from the developmental effort will be suitable for adaptation to lunar sortie and long-term VSE goals to achieve an expanded human presence in the solar system.

\section{Summary}

The result from a process technology developmental effort based on a functional, unit operation approach is an energy and volume efficient cabin atmosphere revitalization process that is highly reliable and easily maintained. Attention to robust design principles lead to stage-wise optimization that addresses top level performance considerations to yield the most efficient process design. By developing a more efficient end-to-end process design, redundancy can be better addressed using multiple process strings. As well, a well-designed, modular atmosphere revitalization process built around core process technologies can be easily modified by adding other unit operations to recover resources thus moving toward ECLS system closure to build a solid platform to expand human presence in the solar system. Such a closed-system design will fully enable the most challenging VSE goals.

\section{Conclusion}

The NASA possesses an extensive working historical and operational knowledge base from which the next generation of atmosphere revitalization process designs will benefit. Given the urgency to deliver process technology products to new space exploration vehicle programs, leveraging experience gained during the design, development, and operation of the process equipment on board the Shuttle orbiter and the ISS is vital to successfully meeting the challenges presented by the VSE. These challenges can be addressed by implementing a functional, unit operations-driven approach to core process technology identification, selection, and characterization as well as using robust design principles to optimize the end-to-end process.

\section{References}

l“"The Vision for Space Exploration," NASA, NP-2004-01-334-HQ, February 2004.

${ }^{2}$ Diamant, B.L. and Humphries, W.R., "Past and Present Environmental Control and Life Support Systems on Manned Spacecraft," Society of Automotive Engineers, 901210, 1990.

${ }^{3}$ Wieland, P.O., "Living Together in Space-The Design and Operation of the Life Support Systems on the International Space Station," NASA/TM-206956, Vol. 1., January 1998.

${ }^{4}$ Wieland, P.O.: "Designing for Human Presence in Space-An Introduction to Environmental Control and Life Support Systems,"NASA RP-1324, 1994.

${ }^{5}$ Martin, C.E., "Environmental Control and Life Support System Historical Data Summary-Apollo through Space Station Freedom," McDonnell Douglas Space Systems Co., MDC 92W5038, December 1992.

${ }^{6}$ Wieland, P.O., "Designing for Human Presence in Space: An Introduction to Environmental Control and Life Support Systems. Appendix I, Update-Historical ECLSS for U.S. and U.S.S.R/Russian Space Habitats,” NASA/TM-2005-214007, July 2005.

${ }^{7}$ Lange, K.E., Perka, A.T., Duffield, B.E., and Jeng, F.F., "Bounding the Spacecraft Atmosphere Design Space for Future Exploration Missions," NASA/CR-2005-213689. June 2005.

${ }^{8}$ Papale, B. and Dean, W.C., "Development, Testing, and Packaging of a Redundant Regenerable Carbon Dioxide Removal System," Society of Automotive Engineers, 2002-01-2530, 2002.

9"Investigation and Testing of Low Temperature Carbon Monoxide Catalysts," Lockheed Missiles and Space Co., Inc., LMSC/D556669, January 1977. 1981.

${ }^{10}$ Kissenger, L.D., “Orbiter Ambient Temperature Catalytic Oxidizer Performance Certification," NASA, CSD-SH-208, 
${ }^{11}$ Perry, J.L., "Elements of Spacecraft Cabin Air Quality Control Design," NASA/TP-1998-207978, May 1998; pp. 60-61,

${ }^{12}$ Tatara, J., Perry, J., and Franks, G., "International Space Station System-Level Trace Contaminant Injection Test," NASA/TM-1999-209010, March 1999.

${ }^{13}$ Perry, J.L., "The Interaction of Spacecraft Cabin Atmospheric Quality and Water Processing System Performance," Society of Automotive Engineers, 2002-01-2300, 2002.

${ }^{14}$ Ray, C.D., Littles, J.W., Blair, J.L., and Jagow, R.B., "Design and Development of a Trace Contaminant Removal Canister for Spacelab," American Society of Mechanical Engineers, ASME 79-ENAs-16, 1979.

${ }^{15}$ Ray, C.D. and Stanley, J.B., "Spacelab Baseline ECS Trace Contaminant Removal Test Program," NASA TM 78135, September 1977.

${ }^{16}$ Knox, J.C., "International Space Station Carbon Dioxide Removal Assembly Testing," Society of Automotive Engineers, 2000-01-2345, 2000.

${ }^{17}$ Wieland, P.O., "Living Together in Space: The Design and Operation of the Life Support Systems on the International Space Station," NASA/TM-1998-206956/Vol. 1, January 1998, pp. 121-139.

${ }^{18}$ Perry, J.L., Curtis, R.E., Alexandre, K.L., Ruggiero, L.L., and Shtessel, N., "Performance Testing of a Trace Contaminant Control Subassembly for the International Space Station," Society of Automotive Engineers, 981621, 1998.

${ }^{19}$ Carrasquillo, R., Cloud, D., and Kundrotas, R., "Status of the Node 3 Regenerative ECLSS Water Recovery and Oxygen Generation Systems," Society of Automotive Engineers, 2004-01-2384, 2004, pp. 8-10.

${ }^{20}$ Bagdigian, R. and Cloud, D., "Status of the International Space Station Regenerative ECLSS Water Recovery and Oxygen Generation Systems," Society of Automotive Engineers, 2005-01-2779, 2005, pp. 5-9.

${ }^{21}$ Perry, J.L., "International Space Station Bacteria Filter Element Service Life Evaluation,” NASA/TM-2005-213846, April 2005.

${ }^{22}$ Carrasquillo, R.L., Wieland, P.O., and Reuter, J.L., "International Space Station Environmental Control and Life Support System Technology Evolution," Society of Automotive Engineers, 961475, 1996.

${ }^{23}$ Carrasquillo, R.L., "ISS ECLSS Technology Evolution for Exploration," American Institute of Aeronautics and Astronautics, AIAA-2005-0337, January 2005.

${ }^{24}$ Perry, J.L., Joshi, J.A., and Kliss, M.H., "A Functional Approach to Advanced Environmental Control and Life Support Technology Development," 2002.

${ }^{25} \mathrm{McC}$ abe, W.L. and Smith J.C., Unit Operations of Chemical Engineering, $3^{\text {rd }}$ ed., McGraw-Hill, New York, 1976 , p. 4.

${ }^{26}$ Jones, H., "Project Selection for NASA's R\&D Programs," Society of Automotive Engineers, 2005-01-2916, 2005.

${ }^{27}$ Jones, H., "Air and Water System (AWS) Design and Technology Selection for the Vision for Space Exploration," Society of Automotive Engineers, 2005-01-2810, 2005, p. 7.

${ }^{28}$ LeVan, M., "Development of Next-Generation Membrane Integrated Adsorption Processor for $\mathrm{CO}_{2}$ Removal and Compression for Closed-Loop Air Revitalization and Analysis of Desiccating Membrane," Society of Automotive Engineers, 2003-01-2367, 2003.

${ }^{29}$ Filburn, T., Nalette, T., and Graf, J., "The Design and Testing of a Fully Redundant Regenerative $\mathrm{CO}_{2}$ Removal System for the Shuttle Orbiter," Society of Automotive Engineers, 2001-01-2420, 2001.

${ }^{30}$ Papale, B. and Dean, W.C., "Development, Testing, and Packaging of a Redundant Regenerable Carbon Dioxide Removal System," Society of Automotive Engineers, 2002-01-2530, 2002.

${ }^{31}$ Roychoudhury, S. and Craciun, R., "A Novel, Integrated Adsorber/Catalytic Oxidizer for TCCS," NAS8-01160, Precision Combustion, Inc.: North Haven, CT; May 2002.

${ }^{32}$ Roychoudhury, S., Muench, G., Bianchi, J.F., Pfefferle, W.C., and Gonzales, F., "Development and Performance of Microlith Light-Off Preconverters for LEV/ULEV," Society of Automotive Engineers, 971023, February 1997.

${ }^{33}$ Carter, R.N., Menacherry, P., Pfefferle, W.C., Muench, G., and Roychoudhury, S., "Laboratory Evaluation of Ultra-short Metal Monolith Catalyst," Society of Automotive Engineers, 980672, February 1998.

${ }^{34}$ Carter, R.N., Bianchi, J.F., Pfefferle, W.C., Roychoudhury, S., and Perry, J.L., "Unique Metal Monolith Catalytic Reactor for Destruction of Airborne Trace Contaminants," Society of Automotive Engineers, 972432, 1997.

${ }^{35}$ Perry, J.L., Carter, R.N., and Roychoudhury, S., "Demonstration of an Ultra-Short Channel Metal Monolith Catalytic Reactor for Trace Contaminant Control Applications," Society of Automotive Engineers, 1999-01-2112, 1999.

${ }^{36}$ Wright, J.D., Bahr, J., Bai, C., Chen, B., Wang, C., Goss, J., and Graf, J., "Development and Testing of a Non-Expendable Contaminant Control System," Society of Automotive Engineers, 972433, 1997.

${ }^{37}$ Graf, J., Wright, J., and Bahr, J., "A Regenerable Sorbent Bed for Trace Contaminant Removal," Society of Automotive Engineers, 1999-01-2071, 1999.

${ }^{38}$ Perry, J.L., Tomes, K.M., and Tatara, J.D., "Thermal Catalytic Oxidation of Airborne Contaminants by a Reactor Using Ultra-Short Channel Length, Monolithic Catalyst Substrates," NASA/TM-2005-214061, September 2005, pp. 35-36.

${ }^{39}$ Ibid, pp. 35-36.

${ }^{40}$ Mulloth, L.M., Perry, J.L., and LeVan, M.D., "Integrated System Design for Air Revitalization in Next Generation Crewed Spacecraft," Society of Automotive Engineers, 2004-01-2373, 2004.

${ }^{41}$ Crew Exploration Vehicle - (CEV), NASA RFP - NNT05AA01J, March 2005.

${ }^{42}$ Exploration Systems Architecture Study (ESAS) Architecture Technology Requirements Summary, June 2005. 